Journal of Mathematics and Statistics 3 (3): 77-79, 2007

ISSN 1549-3644

(C) 2007 Science Publications

\title{
Detecting Non-Dominated Extreme Points for Multiple Objective Linear Programming
}

\author{
S.F. Tantawy \\ Mathematics Department, Faculty of Science, Helwan University (11795) Cairo, Egypt
}

\begin{abstract}
Efficient extreme points in decision space of multiple objective linear programming (MOLP) may not map to non dominated extreme points in objective space under the linear mapping, condition that efficient extreme points have a non dominated extreme is given, the important of this study is that the decision-Maker may depends on extreme points of the set of the objective space than that of the decision space since they have fewer extreme points.
\end{abstract}

Key words: Multiple objective linear program, efficient point, non-dominated point

\section{INTRODUCTION}

The multiple objectives linear programming (MOLP) problems arises when several linear objective functions has to be maximized (or minimized) on a convex polytope. Different approaches have been suggested for solving this problem, among which are the ones suggested by ${ }^{[1-6]}$. More researches involve the objective space analysis of multiple objective linear programming has been studied by ${ }^{[7]}$ also relation between faces of the decision space and those of the objective space was investigated by ${ }^{[8]}$, the reason for this investigation is that the objective space may have fewer dimension than those of the decision space under the linear mapping.

Notations and theory: Multiple objective linear programming (MOLP) problems arises when several linear objective functions has to be maximized (or minimized) on a convex polytope.

$\mathrm{X}=\left\{\mathrm{x}-\mathrm{R}^{\mathrm{m}} / \mathrm{Ax}=\mathrm{b}, \mathrm{x} \geq 0\right\}$

Where $\mathrm{A}$ is an $\mathrm{m} \times \mathrm{n}$ matrix and $\mathrm{b} \_\mathrm{R}^{\mathrm{m}}$.

If $\mathrm{C}$ is a $\mathrm{k} \mathrm{x} \mathrm{n}$ matrix, then (MOLP) can be formulated as:

Maximize $\mathrm{y}=\mathrm{C} \mathrm{x}$

Subject to $\mathrm{x}-\mathrm{X}$

Solving (MOLP) problem is to find the set of efficient solution $\mathrm{E}$ where

$\mathrm{E}=\{\mathrm{x}-\mathrm{X} \mid$ there is no

$\bar{x} \_\mathrm{X}$ such that $\mathrm{C} \mathrm{x} \leq \mathrm{C} \bar{x}$,

Consider the set

$\mathrm{Y}=\left\{\mathrm{y}-\mathrm{X}^{\mathrm{K}} \mid \mathrm{y}=\mathrm{Cx}, \mathrm{x}-\mathrm{X}\right\}$
Then we say that $y$ is non dominated point if

$\mathrm{y}-\mathrm{Y}$ and there is no $\overline{\mathrm{y}}-\mathrm{Y}$ such that

$\mathrm{y} \leq \overline{\mathrm{y}}$.For (MOLP) problem defined by (1.1) if $\mathrm{x}$ is a

basic feasible solution of $\mathrm{A} x=b$,

$\mathrm{x} \geq 0$ with corresponding basic decomposition.

$\left(\begin{array}{cc}A & b \\ -C & 0\end{array}\right)=\left(\begin{array}{ccc}B & N & b \\ -C_{B} & -C_{N} & 0\end{array}\right)$

The canonical simplex tableau for $\mathrm{x}$ in multiple objective forms can be defined as:

$$
\mathrm{T}(\mathrm{x})=\left(\begin{array}{ccc}
\mathrm{I} & \mathrm{B}^{-1} \mathrm{~N} & \mathrm{~B}^{-1} \mathrm{~b} \\
0 & \mathrm{R} & \mathrm{y}
\end{array}\right)
$$

Here $\mathrm{x}=\left(\mathrm{B}^{-1} \mathrm{~b}, 0\right)^{\mathrm{T}}, \mathrm{y}=\mathrm{Cx}-\mathrm{R}^{\mathrm{K}}$ is a

$\mathrm{kx}(\mathrm{n}-\mathrm{m})$ matrix of reduced cost coefficients for each of the $\mathrm{k}$ objectives defined by

$\mathrm{R}=\mathrm{C}_{\mathrm{B}} \mathrm{B}^{-1} \mathrm{~N}-\mathrm{C}_{\mathrm{N}}$

It is will none result in (MOLP) due to ${ }^{[9]}$ that if $x^{0}$ is an non degenerate extreme point of $\mathrm{X}$ with reduced cost coefficient matrix $R$, then $x^{0}$ is efficient if and only if there exist a $\lambda-\mathrm{R}^{\mathrm{K}}$ with $\lambda>0$ such that $\lambda^{\mathrm{T}}$ $\mathrm{R} \geq 0$.

Dauer $^{[7]}$, suggested solving a linear programming problem to find extreme non dominated points in $\mathrm{Y}$ depending on definition of a frame $\mathrm{F}(\mathrm{Y})$ of all column of $\mathrm{R}$, then pivoting in column $\mathrm{r}_{\mathrm{J}}{ }^{0}-\mathrm{F}(\mathrm{Y})$ an adjacent

Corresponding Author: $\quad$ S .F. Tantawy, Mathematics Department, Faculty of Science, Helwan University (11795), Cairo, Egypt 
extreme points $\overline{\mathrm{x}}-\mathrm{X}$ with extreme point $\overline{\mathrm{y}}-\mathrm{Y}$ can be found by solving the linear program

Maximize $\theta$

Subject to:

$\mathrm{Ax}=\mathrm{b}$

$\mathrm{Cx}+\theta \mathrm{r}_{\mathrm{J}}^{0}=\mathrm{C} \mathrm{x^{0 }}$

$\mathrm{x} \geq 0, \theta \geq 0$,

Also he characterized when $\overline{\mathrm{y}}=\mathrm{C} \overline{\mathrm{x}}$ is an extreme point of $Y$ through the following theorem ${ }^{[7]}$. Let $x^{0}$ be an extreme point of $\mathrm{X}$ such that $\mathrm{y}=\mathrm{C} \mathrm{x}{ }^{0}$ lies on an edge of $\mathrm{Y}$ and suppose $\mathrm{r}_{J}^{0}$ a column from $\mathrm{R}$ in $\mathrm{T}\left(\mathrm{x}^{0}\right)$, corresponding to the edge of $Y$ pivoting in $\mathrm{r}_{\mathrm{J}}^{0}$ in $\mathrm{T}\left(\mathrm{x}^{0}\right)$ yields the resulting extreme point $\overline{\mathrm{x}}-\mathrm{X}$, then $\overline{\mathrm{y}}=\mathrm{C} \overline{\mathrm{x}}$ is an extreme point of $Y$ if and only if for each $\bar{r}_{i}$ in $T$ $(\bar{x})$ with $\bar{\theta}_{i}>0$, we have $r_{J}^{0} \neq \beta \bar{r}_{i}$ for any scalar $\beta>0$.

Condition for extreme point in $\mathbf{X}$ to have extreme point in Y: In analogy we need more price sly condition for detecting whether or not the resulting efficient point maps to non dominated extreme points in $\mathrm{Y}$, depending on the above theorem, we have the following theorem.

Theorem 3.1: Let $x^{0}$ be an efficient non degenerate extreme point of $X$ and suppose $r_{J}^{0}$ a column from $R$ in $\mathrm{T}\left(\mathrm{x}^{0}\right)$, pivoting on $\mathrm{r}_{\mathrm{J}}^{0}$ in $\mathrm{T}\left(\mathrm{x}^{0}\right)$ yields the resulting extreme point $\overline{\mathrm{x}} \_\mathrm{X}$. then $\overline{\mathrm{y}}=\mathrm{C} \overline{\mathrm{x}}$ is an extreme point of $Y$ if there exist a solution $\lambda>0$ to the system

$\lambda^{\mathrm{T}} \bar{R} \geq 0$

$-\lambda^{\mathrm{T}} \mathrm{r}_{\mathrm{J}}^{0} \geq 1$

where $\overline{\mathrm{R}}$ is the reduced cost coefficient matrix corresponding to $\bar{x}$.

Proof: Since $\overline{\mathrm{x}}$ is efficient then $\lambda^{\mathrm{T}} \overline{\mathrm{R}} \geq 0$ has a solution $\lambda>0$ where $\overline{\mathrm{R}}$ is the reduced coefficient matrix corresponding to $\bar{x}$ and if there exist scalar $\beta^{*}>$ 0 such that $\beta^{*} \mathrm{r}_{\mathrm{J}}^{0}=\overline{\mathrm{r}}_{\mathrm{i}}, \mathrm{i}-1,2 \ldots, \mathrm{n}-\mathrm{m}$, then

$\lambda^{\mathrm{T}} \overline{\mathrm{R}} \geq 0$

$-\lambda^{\mathrm{T}} \bar{r}_{\mathrm{i}} \geq \beta^{*}$

Has no solution $\lambda>0$, hence there exist solution only when $\beta^{*} \mathrm{r}_{\mathrm{J}}^{0} \neq \overline{\mathrm{r}}_{\mathrm{i}}$ or $\mathrm{r}_{\mathrm{J}}^{0} \neq \beta \overline{\mathrm{r}}_{\mathrm{i},} \beta=1 / \beta^{*}$.

Depending on the linear program defined by (2.7), suppose $\theta^{*}$ solves this linear program then we have the following corollary
Corollary 3.1: Let $x^{0}$ be an efficient non degenerate extreme point of $\mathrm{X}$ and suppose $\mathrm{r}_{\mathrm{J}}^{0}$ a column from $\mathrm{R}$ in $\mathrm{T}\left(\mathrm{x}^{0}\right)$, pivoting on $\mathrm{r}_{\mathrm{J}}^{0}$ in $\mathrm{T}\left(\mathrm{x}^{0}\right)$ yields the resulting extreme point $\overline{\mathrm{x}}-\mathrm{X}$. then $\overline{\mathrm{y}}=\mathrm{C} \overline{\mathrm{x}}$ is an extreme point of $Y$ if there exist a solution $\lambda>0$ to the system

$\lambda^{\mathrm{T}} \overline{\mathrm{R}} \geq 0$

$\lambda^{\mathrm{T}}\left(\overline{\mathrm{y}}-\mathrm{y}^{0}\right) \geq \theta *$

Proof: Straight forward

Remark 3.1: Since for the feasible efficient $\bar{x}$ the system of inequalities $\lambda^{T} \bar{R} \geq 0$ must have the solution $\lambda>0$, then the reset is just to insert the inequality $-\lambda^{\mathrm{T}}$ $\mathrm{r}_{\mathrm{J}}^{0} \geq 1$ and test for feasibility to insure whether or not the corresponding $\overline{\mathrm{y}}=\mathrm{C} \overline{\mathrm{x}}$ is extreme or not .

Example: This example is taken from ${ }^{[10]}$ consider the (MOLP) problem.

Maximize: $\mathrm{y}_{1}=\mathrm{x}_{1}+1 / 2 \mathrm{x}_{2}$

Subject to

$$
\mathrm{y}_{2}=1 / 2 \mathrm{x}_{2}+\mathrm{x}_{3}
$$

$\mathrm{x}_{1}+\mathrm{x}_{2}+\mathrm{x}_{3} \leq 3$

$2 x_{1}+1 / 2 x_{2}-x_{3} \leq 2$

$\mathrm{x}_{\mathrm{i}} \geq 0, \quad \mathrm{i}=1,2,3$
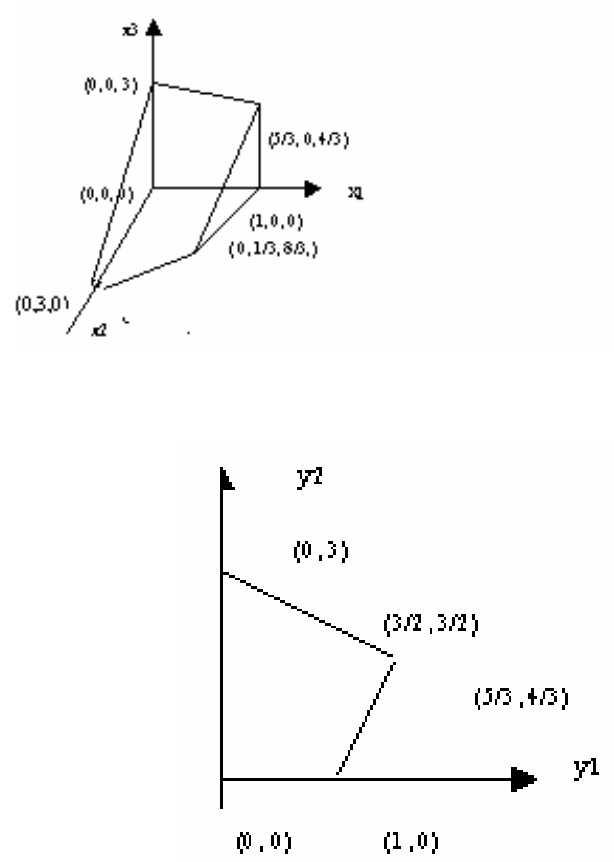

Only $(0,3)$ and $(5 / 3,4 / 3)$ are extreme in $Y$.

Let $\mathrm{x}^{0}$ be an efficient extreme in $\mathrm{x}$ with tableau given bellow. 


\begin{tabular}{l|lllll|l} 
Basic & $\mathrm{x}_{1}$ & $\mathrm{x}_{2}$ & $\mathrm{x}_{3}$ & $\mathrm{~s}_{1}$ & $\mathrm{~s}_{2}$ & solution \\
\hline $\mathrm{x}_{3}$ & 1 & 1 & 1 & 1 & 0 & 3 \\
$\mathrm{~s}_{2}$ & 3 & $3 / 2$ & 0 & 1 & 1 & 5 \\
\hline & -1 & $-1 / 2$ & 0 & 0 & 0 & 0 \\
1 & $1 / 2$ & 0 & 1 & 0 & 3 \\
$\mathrm{x}^{0}=$ & $(0,0,3), \mathrm{y}^{0}=(0,3)$
\end{tabular}

Pivoting in column 2 will yield

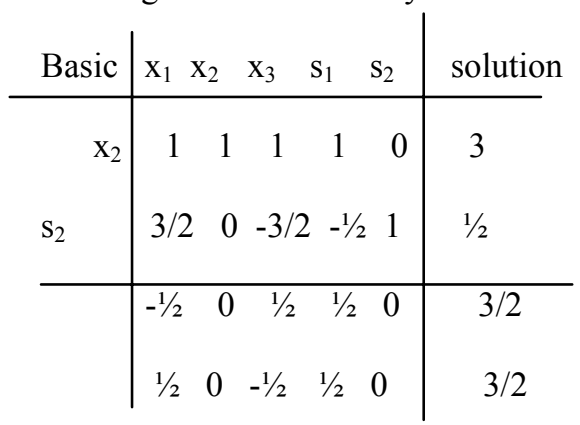

$x^{1}=(0,3,0), y^{1}=(3 / 2,3 / 2)$

Since the system

$-\lambda_{1}+\lambda_{2} \geq 0$

$+\lambda_{1}-\lambda_{2} \geq 0$

$\lambda_{1}-\lambda_{2} \geq 2$,

does not have a solution this indicates that $\mathrm{x}^{1}=(0,3,0)$ which is extreme efficient in $\mathrm{x}$ its image

$y^{1}=(3 / 2,3 / 2)$ in not extreme in $Y$ on the other hand pivoting in column 1 yield.

\begin{tabular}{l|ccccc|c} 
Basic & $\mathrm{x}_{1}$ & $\mathrm{x}_{2}$ & $\mathrm{x}_{3}$ & $\mathrm{~s}_{1}$ & $\mathrm{~s}_{2}$ & solution \\
\hline $\mathrm{x}_{3}$ & 0 & $1 / 2$ & 1 & $2 / 3$ & $-1 / 3$ & $4 / 3$ \\
$\mathrm{x}_{1}$ & 1 & $1 / 2$ & 0 & $1 / 3$ & $1 / 3$ & $5 / 3$ \\
\hline & 0 & 0 & 0 & $1 / 3$ & $1 / 3$ & $5 / 3$ \\
& 0 & 0 & 0 & $2 / 3$ & $-1 / 3$ & $4 / 3$ \\
$\mathrm{x}^{2}=(5 / 3,0,4 / 3), \mathrm{y}^{2}=(5 / 3,4 / 3)$ & \\
And the system \\
$\lambda_{1}+2 \lambda_{2} \geq 0$ \\
$\lambda_{1}-\lambda_{2} \geq 0$ \\
$\lambda_{1}-\lambda_{2} \geq 1$
\end{tabular}

Has a solution indicating that $\mathrm{y}_{2}$ is an extreme non dominated point in $\mathrm{y}$.

\section{CONCLUSION}

In this study we give a condition for an efficient extreme points in the decision space of multiple objectives lineal programming problem to have a non dominated extreme points in the objective space under the linear mapping, the important of this study is that Decision-Maker may depends on extreme points of the set of the objective space since they have fewer extreme points than that of the decision space.

\section{REFERENCES}

1. Evans, J.P. and R.F. Steven, 1973. Generating efficient extreme points in linear multiple objective programming two algorithms and computing experience in Cochran and Zeleny. Multiple Criteria Decision Making, University of South Carolina Press.

2. Tamura, K and S. Mura, 1997. On linear vector maximization problems. J. Oper. Res. Soc., Japan, 1077: 139-149.

3. Gal, T.A., 1977. General method for determining the set of all efficient solution to a linear vector maximum problem. Eur. J. Oper. Res., 1: 307-322.

4. Isermann, H., 1977. The enumeration of the set of all efficient solution for a linear multiple objective program. Oper. Res. Quart., 28: 711-725.

5. Ecker, J.G. and I.A. Kauda, 1978. finding all efficient extreme points for multiple objective linear programming. Math. Program., 14: 249-261.

6. Ecker, J.G., H.S. Hegren and I.A. Kauda, 1980. Generating maximal efficient faces for multiple objective linear programs. J. Optimization Theory and Application, 30: 353-361.

7. Dauer, J.P. and L.H. Liu, 1990. Solving multiple objective linear programs in objective space. E. J. Oper. Res., 64: 350-357.

8. Dauer, J.P., 1987. Analysis of the objective space in multiple objective linear programming. J. Math. Anal. Applic., 126: 579-593.

9. Zeleny, M., 1974. Linear Multiobjective programming. Springer-Verlag, New York.

10. Sebo, D.E., 1981. Multiple objective linear programming in objective space. Ph.D. Thesis, University of Nebraska-Lincoln. 